\title{
Novas espécies de Neocorini e Pteropliini (Coleoptera, Cerambycidae) da América do Sul
}

\author{
Maria Helena M. Galileo ${ }^{1,3}$ \& Ubirajara R. Martins ${ }^{2,3}$
}

\author{
1 Museu de Ciências Naturais, Fundação Zoobotânica do Rio Grande do Sul. Caixa Postal 1188, 90001-970 Porto Alegre, \\ Rio Grande do Sul, Brasil. \\ 2 Museu de Zoologia, Universidade de São Paulo. Caixa Postal 42494, 04218-970 São Paulo, São Paulo, Brasil. \\ ${ }^{3}$ Pesquisador do CNPq.
}

\begin{abstract}
New species of Neocorini and Pteropliini (Coleoptera, Cerambycidae) from South America. New species described in Neocorini: Marauna bucki sp. nov. (Brazil: Rio Grande do Sul) and M. abati sp. nov. (Paraguai). In Pteropliini: Rhaphiptera boliviana sp. nov. and Ataxia cineracea sp. nov. (Bolivia: Santa Cruz). KEY WORDS. Cerambycinae; Lamiinae; taxonomy.
\end{abstract}

RESUMO. Novas espécies descritas em Neocorini: Marauna bucki sp. nov. (Brasil: Rio Grande do Sul) e M. abati sp. nov. (Paraguai). Em Pteropliini:; Rhaphiptera boliviana sp. nov. e Ataxia cineracea sp. nov. (Bolívia: Santa Cruz). PALAVRAS-CHAVE. Cerambycinae; Lamiinae; taxonomia.

Martins \& Galileo (2006) estabeleceram o gênero Marauna (Neocorini) para M. punctatissima Martins \& Galileo, 2006, espécie conhecida da Bolívia. Descobrimos agora mais duas espécies deste gênero que ampliam sua distribuição para o Brasil (Rio Grande do Sul) e para o Paraguai.

A tribo Pteropliini, que atualmente conta com 14 gêneros, foi revista por BREUNING (1961). Após essa revisão foram feitas algumas contribuições: Fragoso \& Monné (1984) estudaram o gênero Rhaphiptera Audinet-Serville, 1853 e GALILEO \& M ARTINS (2002) revisaram o gênero Anobrium Belon, 1902. Descrevem-se a seguir duas espécies novas da Bolívia, Santa Cruz, Rhaphiptera boliviana e Ataxia cineracea.

$O$ material citado no texto pertence às seguintes instituições: ACMB, American Coleoptera Museum, San Antonio, Estados Unidos; FSCA, Florida State Collection of Athropods, Gainesville, Estados Unidos; MCNZ, Museu de Ciências Naturais, Fundação Zoobotânica do Rio Grande do Sul, Porto Alegre, Brasil; MNKM, Museo de Historia Natural Noel Kempff Mercado, Santa Cruz, Bolívia; MZSP, Museu de Zoologia, Universidade de São Paulo, São Paulo, Brasil.

\section{Cerambycinae, Neocorini \\ Marauna bucki sp. nov.}

Fig. 1

Etimologia. O epíteto é uma homenagem póstuma ao $\mathrm{Pe}$ Pio Buck coletor do holótipo.
Cabeça com tegumento castanho-escuro menos no vértice, com tegumento avermelhado e mancha de pubescência esbranquiçada no meio. Lobos oculares superiores com quatro fileiras de omatídios, tão distantes entre si quanto o quíntuplo da largura de um lobo. Antenas pretas ou castanho-escuras.

Protórax castanho-escuro com a borda anterior avermeIhada; no pronoto, a borda avermelhada é coberta por pubescência esbranquiçada. Pronoto com quatro gibosidades apenas indicadas; pontuação muito densa, menos sobre a orla anterior.

Élitros acastanhados com o friso marginal e a parte lateral, amarelados; densamente pontuados em toda a superfície; extremidades subarredondadas.

Face ventral do corpo densamente pontuada; tegumento dos urosternitos mais avermelhado. Fêmures com pedúnculo avermelhado e clava acastanhada. Protíbias castanhas; mesotíbias castanhas com a base avermelhada; metatíbias avermelhadas.

Dimensões em milímetros, holótipo fêmea/parátipo fêmea. Comprimento total, 5,5 /5,4; comprimento do protórax, $1,1 / 1,1$; maior largura do protórax, 0,9/0,9; comprimento do élitro, 4,0/3,8; largura umeral, 1,2 /1,2.

Material-tipo. Holótipo fêmea, BRASIL, Rio Grande do Sul: Porto Alegre, 6.X.1948, [P. Buck leg.] (MCNZ); parátipo fêmea, 12.X.1931, [P. Buck leg.] (MZSP).

Discussão. O colorido geral de Marauna bucki sp. nov. separa-a de M. punctatissima Martins \& Galileo, 2006 que tem a cabeça e protórax avermelhados e élitros alaranjados.

Revista Brasileira de Zoologia 24 (1): 203-206, março 2007 

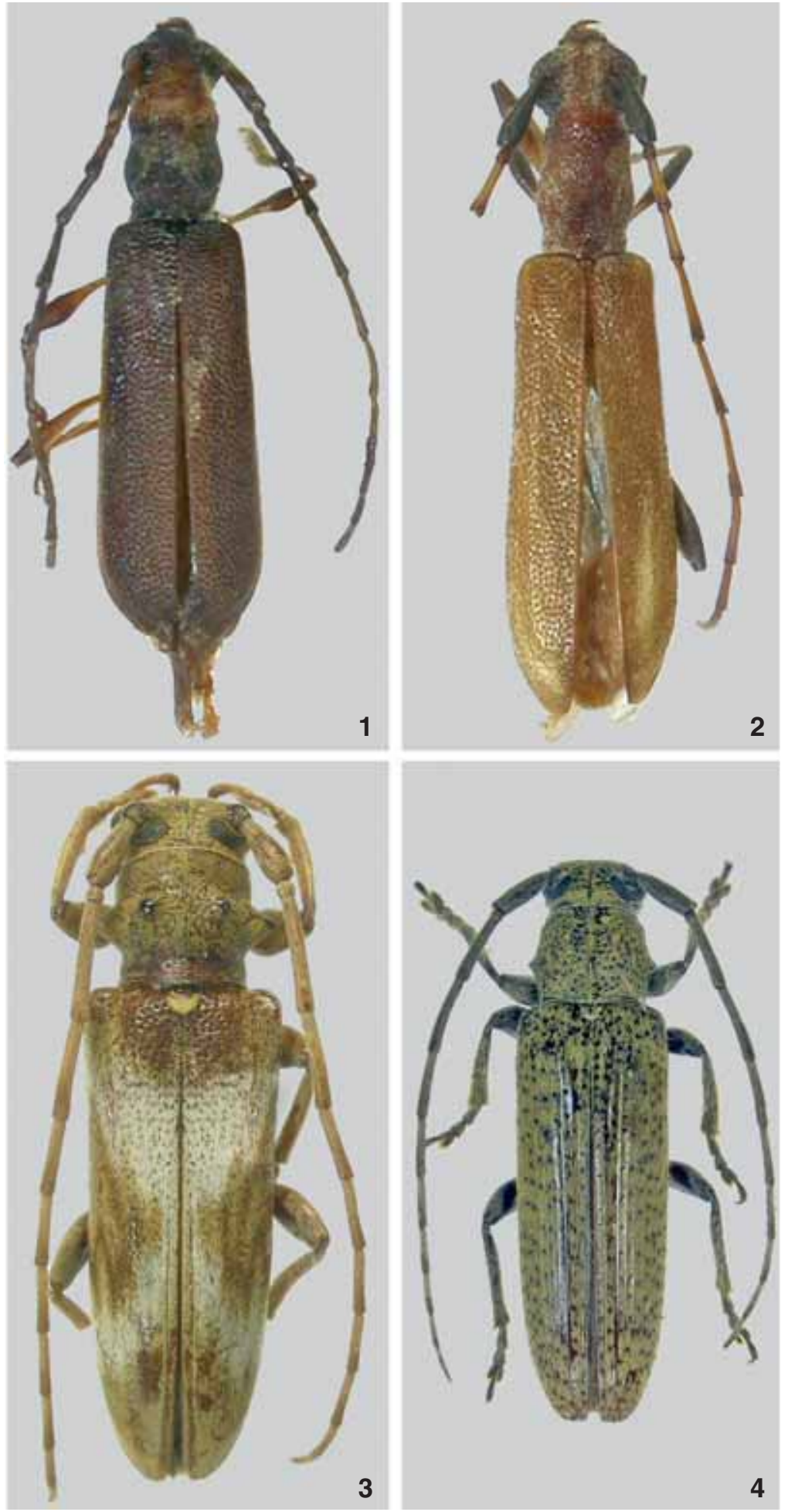

Figuras 1-4. (1) Marauna bucki sp. nov., holótipo fêmea, comprimento 5,5 mm; (2) Marauna abati sp. nov., holótipo macho, comprimento 6,5 mm; (3) Rhaphiptera boliviana sp. nov., holótipo fêmea, comprimento 14,1 mm; (4) Ataxia cineracea sp. nov., comprimento $13,0 \mathrm{~mm}$. 


\section{Marauna abati sp. nov.}

Fig. 2

Etimologia. Tupi, abati = milho, referente à coloração amarelo-alaranjada dos élitros que lembra a cor do milho.

Cabeça com tegumento avermelhado. Fronte e região entre os lobos oculares superiores com pubescência brancoamarelada. Lobos oculares superiores com cinco fileiras de omatídios; mais distantes entre si que o dobro da largura de um lobo. Escapo preto; pedicelo acastanhado; flagelômeros avermeIhados exceto o ápice dos antenômeros III a VIII, acastanhado.

Protórax avermelhado com os três quartos posteriores do prosterno pretos. Partes laterais do protórax densa e fortemente pontuadas e os interstícios dos pontos da região basal com pilosidade esbranquiçada. Lados do pronoto com pubescência esbranquiçada, moderadamente esparsa de tal forma que permite visualizar a pontuação; no adel gaçamento basal, de cada lado, pequeno tufo de pêlos branco-amarelados.

Élitros amarelo-alaranjados, pontuados em toda a superfície, sem pubescência entre os pontos. Extremidades elitrais arredondadas.

Mesosterno, metasterno e urosternito I preto-avermel hados e densamente pontuados. Urosternitos II-IV avermel hados.

Fêmures com pedúnculo alaranjado e clava preta. Tíbias alaranjadas com os ápices levemente acastanhados.

Dimensões em milímetros, holótipo macho. Comprimento total, 6,5; comprimento do protórax, 1,4; maior largura do protórax, 0,9; comprimento do élitro, 4,4; largura umeral, 1,3.

Material-tipo. Holótipo macho, Paragual, Central: Lambaré, 9.X.1989, S. Castro leg. (MCNZ).

Marauna abati sp. nov. assemelha-se a M. punctatissima e difere pelo aspecto geral mais compacto e pelos élitros glabros. Em M. punctatissima (Martins \& Galileo 2006, fig. 6), o aspecto geral é mais esbelto e os élitros têm pubescência branca entre os pontos, principalmente na metade apical.

\section{Lamiinae, Pteropliini Rhaphiptera boliviana sp. nov.}

Fig. 3

Cabeça com tegumento preto-avermel hado revestido por pubescência amarelada. Lobos oculares superiores com seis fileiras de omatídios; tão distantes entre si quanto o dobro da largura de um lobo. Antenas das fêmeas apenas mais longas que o corpo, revestidas por pubescência amarelada.

Protórax coberto por pubescência amarelada; ápice dos tubérculos dorsais e laterais pretos e brilhantes. Pontuação do protórax parcialmente encoberta pela pubescência. Escutelo com pubescência amarelada, densa, oblitera o tegumento.

Élitros revestidos por pubescência branca exceto nas áreas: no quinto basal, transversalmente, com pubescência amarelada; no meio, mancha lateral, triangular, fundida com a margem e sem tocar a sutura, engl oba faixas indistintas de pubescência acastanhada; no quarto apical com pubescência amare- lada. Na região recoberta por pubescência branca, são visíveis pontos pequenos e esparsos. Ápices elitrais arredondados.

Face ventral do corpo e pernas revestidas por pubescência amarelada.

Dimensões em milímetros, holótipo fêmea/parátipo fêmea. Comprimento total, 13,9/14,1; comprimento do protórax, 2,8/2,7; maior largura do protórax, 3,7/3,8; comprimento do élitro, 10,3/10,3; largura umeral, 4,0/4,1.

Material-tipo. Holótipo fêmea, BoliviA, Santa Cruz: Buena Vista (Hotel Flora \& Fauna, 4-6 km SSE), 22-31.X.2002, Wappes $\&$ Morris leg. (M NKM); parátipo fêmea, Buena Vista (Hotel Flora \& Fauna, $5 \mathrm{~km} \mathrm{SSE}, 17^{\circ} 29^{\prime} 96^{\prime \prime} \mathrm{S}, 63^{\circ} 39^{\prime} 13^{\prime \prime} \mathrm{W}, 440 \mathrm{~m}$ ), 30.XI.2004, R. Clarke leg. "white light" (MZSP).

Discussão. Rhaphiptera boliviana sp. nov. assemel ha-se vagamente à R. annulicornis Gounelle, 1908, mas além das dimensões menores, difere pelas extremidades elitrais arredondadas, pela área transversal de pubescência amarelada da base dos élitros, pel os pontos do protórax menores e menos contrastantes, pel os lobos oculares superiores com seis fileiras de omatídios e pela ausência de pubescência esbranquiçada na face ventral do corpo. Em R. annulicornis, as dimensões são maiores, as extremidades elitrais são acuminadas, a base dos élitros tem mancha triangular de pubescência vermelho-alaranjada, os lobos oculares superiores têm oito fileiras de omatídios e a face ventral é coberta por pubescência esbranquiçada no centro do metasterno e dos urosternitos.

\section{Ataxia cineracea sp. nov.}

Fig. 4

Etimologia. Latim, cineracea = coloração cinza; referente à pubescência corporal.

Tegumento corporal preto revestido por pubescência amarelo-acinzentada na face dorsal. Lobos oculares superiores com cinco fileiras de omatídios separados entre si por mais do que o dobro da largura de um lobo. Antenas apenas ultrapassam o ápice dos élitros. Protórax com espículo lateral reduzido. Pronoto fina e densamente pontuado. Partes laterais do protórax e prosterno revestidos por pubescência esbranquiçada. Élitros pontuados em toda exten são; pontos mais grossos e mais aproximados na base; extremidades arredondadas. Face ventral com pubescência esbranquiçada. Lados do metasterno lisos. Lados dos urosternitos com pontos contrastantes. Último urosternito da fêmea intumescido e fortemente deprimido no meio da borda apical.

Dimensões em milímetros, fêmea. Comprimento total, 11,6-13,0; comprimento do protórax, 2,1-2,3; maior largura do protórax, 2,7-3,1; comprimento do élitro, 8,6-9,4; largura umeral, 3,4-3,6.

Material-tipo. Holótipo fêmea BoLiviA, Santa Cruz: Buena Vista, 3-5.X.1992, E. Giesbert leg. (FSCA). Parátipos - BoLiviA, Santa Cruz: Buena Vista (Hotel Fauna \& Flora, 4-6 km SSE), fêmea, 23-26.X.2000, Wappes \& Morris leg. (ACMB); fêmea, 2729.X.2000, Wappes \& Morris leg. (MZSP); fêmea, 2-12.II.2000, J. E. Wappes leg., "transition tropical forest" (MZSP). 
Discussão. Ataxia cineracea distingue-se de A. obscura (Fabricius, 1801), da Guiana Francesa e do Brasil (Pará), pelo tegumento preto e pubescência amarelo-acinzentada na face dorsal, pelas antenas e pernas pretas, pelo ápice dos élitros arredondado e pela ausência de faixas longitudinais no pronoto. Em A. obscura, o tegumento é avermelhado e a pubescência é branca na face dorsal, as antenas e pernas são avermelhadas, os ápices dos élitros têm espinho externo e o pronoto tem faixa longitudinal, central, de pubescência amarelada.

\section{AGRADECIMENTOS}

Aos pesquisadores que nos enviaram material, James Wappes (ACMB), Sergio Castro Martinez, Santiago, Chile que doaram, respectivamente, para o MZSP, parátipos de Rhaphiptera boliviana e R. cineracea e, para o MCNZ, o holótipo de Marauna abati. A Rafael Santos de Araujo (MCNZ) pela execução das fotografias ea Eleandro Moysés (MCNZ) pelo tratamento das imagens.

\section{REFERÊNCIAS BIBLIOGRÁFICAS}

Breuning, S. 1961. Révision des Pteropliini. Pesquisas 9 (5): 5-60. Fragoso, S.A. \& M.A. Monné. 1984. Sinopse do gênero Rhaphiptera Audinet-Serville, 1835 (Pteropliini). Pesquisa Agropecuária Brasileira 19 (9): 1075-1083.

Galileo, M.H.M. \& U.R. Martins. 2002. Gêneros de Pteropliini semelhantes a Trichepectasis Breuning, 1940 (Lamiinae). Papéis Avulsos de Zoologia 42 (2): 13-30.

Martins, U.R. \& M.H.M. Galileo. 2006. Novos táxons de Cerambycinae (Coleoptera, Cerambycidae) da Região Neotropical . Iheringia, Série Zoologia, 96 (2): 173-178.

Recebido em 04.X.2006; aceito em 05.III.2007. 